\title{
An Applied Research of Decision Tree Algorithm in Track and Field Equipment Training
}

\author{
Shaoqing Liu \\ Vocational College, Langfang, Hebei, China \\ Kebin Wang \\ Langfang Health Vocational College, Langfang, Hebei, China
}

Teaching and Research Office of Physical Education, Department of Public Basic Courses, Langfang Health

\begin{abstract}
This paper has conducted a study on the applications of track and field equipment training based on ID3 algorithm of decision tree model. For the selection of the elements used by decision tree, this paper can be divided into track training equipment, field events training equipment and auxiliary training equipment according to the properties of track and field equipment. The decision tree that regards track training equipment as root nodes has been obtained under the conditions of lowering computation cost through the selection of data as well as the application and optimization of ID3 algorithm model.
\end{abstract}

Keywords: decision tree algorithm; track and field equipment training; auxiliary training equipment

\section{INTRODUCTION}

The decision tree model has been deeply studied in China, which mainly aims at classification types of studying random things and has played an obvious role for the sorting, prediction and classification of data. With regards to the sorting of data, the decision tree model respectively classifies each kind of factors from top to bottom. In the corresponding samples, a number of subsets have been divided, and decision-making purposes have been finally achieved by changing nodes and by constant circulation. This kind of recursive mode makes a comparison according to obtained attribute value and achieves each satisfactory path.

In the study of Chinese track and field training equipment, Liang Jianxiu has received higher satisfaction from athletes and coaches by inspecting national track and field team equipment in the paper "an investigation and study on sports apparatus and equipment status quo of national track and field team". Nowadays, with the progress of science, a series of new auxiliary equipment used in athletic training have appeared, for example, drag chute whose resistance can be adjusted, overweight training rope and so on. The auxiliary equipment has enriched training methods and improved training effect.

\section{SEPARATE NARRATIONS OF TRACK AND FIELD TRAINING EQUIPMENT}

(1) Track training equipment

Starting block, hurdle, obstacle hurdle and pool obstacle stand

(2) Field events training equipment
Height is regarded as the basis: high jump sponge mat, pole vault sponge mat, high jump stand, pole vault high jump stand, high jump crossbar, pole vault high jump crossbar.

Distance length is regarded as the basis: discus/hammer throw cage, shot $(4 \mathrm{~kg})$, shot $(7.26 \mathrm{~kg})$, discus $(1 \mathrm{~kg})$, discus $(2 \mathrm{~kg})$, hammer throw $(4 \mathrm{~kg})$, javelin $(600 \mathrm{~g})$ and javelin $(800 \mathrm{~g})$.

(3) Auxiliary training equipment

1. Overweight training rope

2. Adjustable resistance drag chute

3. Agility ladder

\section{ID3 ALGORITHM}

ID3 algorithm is the typical algorithm of decision tree model, which determines the selection criterion of elements by using the method of information gain and determines node divisors by minimizing information entropy. First of all, the evaluation-data as shown in Figure 1 has been acquired. The decision tree will be determined according to the categories of track and field training equipment under the condition of Pass (P) or Negative $(\mathrm{N})$.

Give a domain of definition $U=\left\{s_{1}, s_{2}, \cdots, s_{n}\right\}$, and each element among them can be regarded as a subset:

$$
\operatorname{Entropy}\left(s_{1}, s_{2}, \cdots, s_{m}\right)=-\sum_{i}^{m} \mathrm{p}_{i} \log _{2}\left(\mathrm{p}_{i}\right)
$$

Wherein, $p_{i}$ is the estimation of $S_{i} / s$. The information entropy of positive and negative set $(\mathrm{P}, \mathrm{N})$ is as follows: 
MATEC Web of Conferences

Table 1. Training sample data table

\begin{tabular}{|l|l|l|l|l|}
\hline No. & $\begin{array}{l}\text { Track Training } \\
\text { Equipment(Types) }\end{array}$ & $\begin{array}{l}\text { Field Events Training } \\
\text { Equipment(Types) }\end{array}$ & $\begin{array}{l}\text { Track and Field Auxiliary Training } \\
\text { Equipment (Types) }\end{array}$ & P or N \\
\hline 1 & 2 & 3 & 0 & $\mathrm{P}$ \\
\hline 2 & 2 & 2 & 0 & $\mathrm{~N}$ \\
\hline 3 & 2 & 2 & 1 & $\mathrm{~N}$ \\
\hline 4 & 2 & 3 & 1 & $\mathrm{P}$ \\
\hline 5 & 2 & 2 & 1 & $\mathrm{~N}$ \\
\hline 6 & 2 & 3 & 3 & $\mathrm{P}$ \\
\hline 7 & 3 & 4 & 3 & $\mathrm{P}$ \\
\hline 8 & 3 & 2 & 0 & $\mathrm{~N}$ \\
\hline 9 & 2 & 1 & 0 & $\mathrm{~N}$ \\
\hline 10 & 2 & 3 & 1 & $\mathrm{~N}$ \\
\hline 11 & 2 & 2 & 2 & $\mathrm{P}$ \\
\hline 12 & 2 & 1 & 2 & $\mathrm{~N}$ \\
\hline 13 & 3 & 2 & 1 & $\mathrm{P}$ \\
\hline 14 & 2 & 2 & 2 & $\mathrm{P}$ \\
\hline 15 & 3 & 3 & 1 & $\mathrm{P}$ \\
\hline
\end{tabular}

$I(P, N)=-\frac{P}{P+N} \log \frac{P}{P+N}-\frac{N}{P+N} \log \frac{N}{P+N}$

Take gained element $\mathrm{A}$ as an example, so the gained expectation is as follows:

$\operatorname{Entropy}(A)=-\sum_{j=1}^{v}\left(s_{1 j}+s_{2 j}+\cdots+s_{m j}\right) / s^{*}$

The above is the classical ID3 algorithm of decision tree model.

\section{APPLIED RESEARCH OF OPTIMIZED ID3 ALGORITHM IN TRACK AND FIELD EQUIPMENT TRAINING}

In order to improve operation efficiency, the elements with uneven properties are avoided to be chosen as root nodes. Therefore, reducing computational process, lowering time and quickening the establishment of decision tree are made by changing feature selections.

First of all, suppose that $S(A)$ meets:

$S(A)=\sum_{i}^{v}\left(-p_{i} \ln \frac{p_{i}}{p_{i}+n_{i}}-n_{i} \ln \frac{n_{i}}{p_{i}+n}\right)$

When $x \rightarrow 0, \ln (1+x) \approx x, S(A)$ can be simplified as:

$S(A)=\sum_{i}^{v} \frac{2 p_{i} n_{i}}{p_{i}+n_{i}}$

The operation time has been greatly reduced due to the reduction of logarithmic operation.

According to the gained data in Table 1, by the formula $S(A)=\sum_{i}^{v} \frac{2 p_{i} n_{i}}{p_{i}+n_{i}}$, the following can be gained:
$\mathrm{S}($ track training equipment $)=\frac{3 \times 1}{4}+\frac{5 \times 6}{11}=3.477$

$\mathrm{S}$ (field events training equipment) = $\frac{10 \times 1}{1}+\frac{4 \times 1}{5}+\frac{3 \times 4}{7}+\frac{2 \times 0}{2}=2.514$

$\mathrm{S}$ (track and field auxiliary training equipment) $=$ $\frac{2 \times 0}{2}+\frac{2 \times 1}{3}+\frac{3 \times 3}{6}+\frac{3 \times 1}{4}=2.917$

The above results are normalized to gain:

$\mathrm{Z}$ (track training equipment, field events training equipment, track and field auxiliary training equipment $)=(0.39,0.28,0.33)$

The subtree graph of decision tree has been gained by recursive mode as shown in Figure 1 .

Different elements have been selected as root nodes. In applied research of track and field equipment training, field events training equipment and track and field auxiliary training equipment can also be selected as root nodes to establish the decision tree.

\section{COMPARING WEIGHT SOLUTION OF DECI- SION TREE ALGORITHM}

Criterion layer: influence factors of the scheme. $c_{1}$ is equipment price; $c_{2}$ is applicability; $C_{3}$ is security; $\mathcal{C}_{4}$ is training effect.

Scheme layer: $A_{1}$ is track training equipment; $A_{2}$ is field event training equipment; $A_{3}$ is track and field auxiliary training equipment.

$$
A=\left\{\begin{array}{cccc}
1 & 1 / 3 & 3 & 3 \\
3 & 1 & 5 & 5 \\
1 / 3 & 1 / 5 & 1 & 1 \\
1 / 3 & 1 / 5 & 1 & 1
\end{array}\right\}
$$

After normalization, the summation of each line can be gained. After W normalization, it gains as follows: 


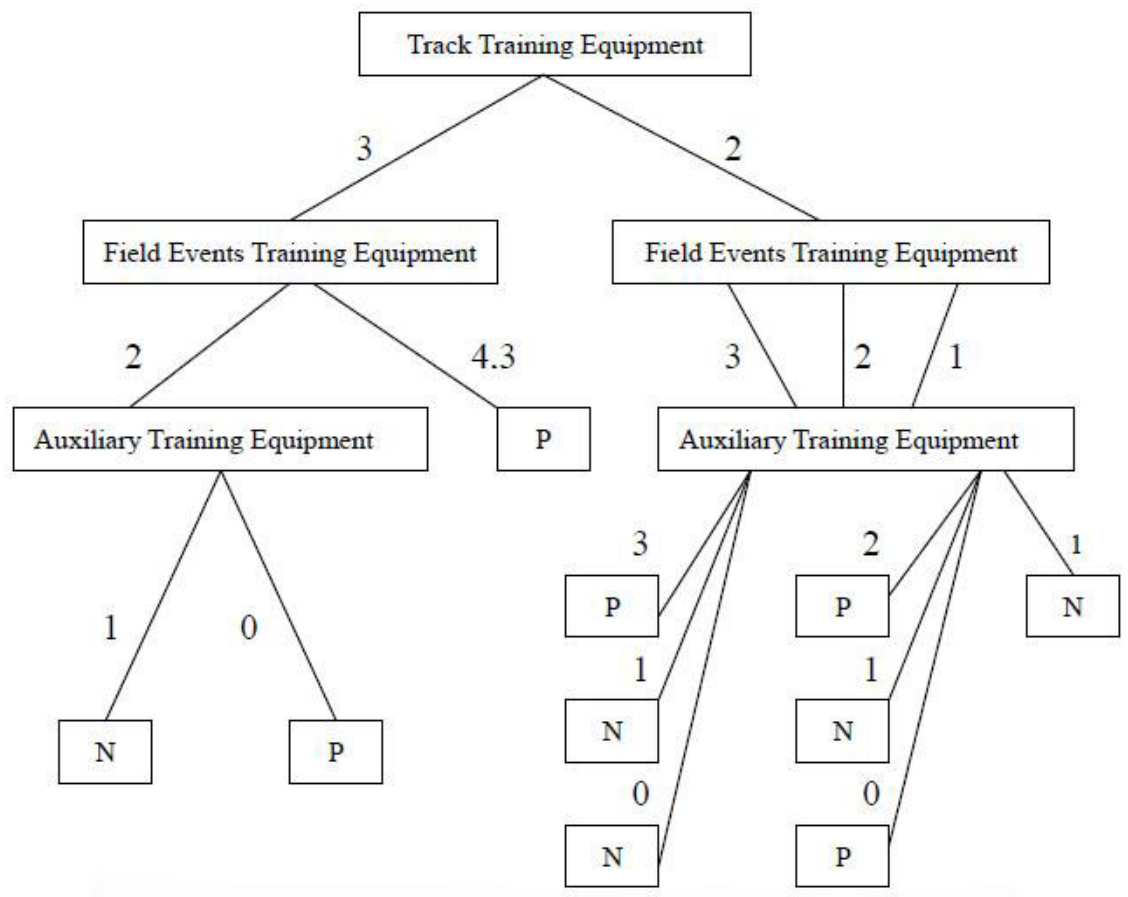

Figure 1. Decision tree graph that takes track training equipment as root node

$$
\mathrm{W}^{(0)}=\left\{\begin{array}{c}
0.2515 \\
0.555 \\
0.0965 \\
0.0965
\end{array}\right\}
$$

It gains as follows:

$A W^{(0)}=\left\{\begin{array}{cccc}1 & 1 / 3 & 3 & 3 \\ 3 & 1 & 5 & 5 \\ 1 / 3 & 1 / 5 & 1 & 1 \\ 1 / 3 & 1 / 5 & 1 & 1\end{array}\right\}\left\{\begin{array}{c}0.2514 \\ 0.555 \\ 0.0965 \\ 0.0965\end{array}\right\}=\left\{\begin{array}{c}1.012 \\ 2.275 \\ 0.387 \\ 0.387\end{array}\right\}$

$\lambda_{\max }^{(0)}=\frac{1}{4}\left(\frac{1.054}{0.257}+\frac{2.254}{0.786}+\frac{0.257}{0.045}+\frac{0.457}{0.078}\right)=4.038$

$w^{(0)}=\left(\begin{array}{c}0.278 \\ 0.56 \\ 0.045 \\ 0.098\end{array}\right)$

In a similar way, the judgment matrix can be figured out:

$B_{1}=\left\{\begin{array}{ccc}1 & 1 & 1 / 3 \\ 2 & 1 & 1 / 3 \\ 3 & 6 & 1\end{array}\right\}, B_{2}=\left\{\begin{array}{ccc}1 & 5 & 5 \\ 1 / 5 & 1 & 2 \\ 1 / 5 & 1 / 5 & 1\end{array}\right\}$,

$B_{3}=\left\{\begin{array}{ccc}1 & 6 & 8 \\ 1 / 5 & 1 & 5 \\ 1 / 8 & 1 / 5 & 1\end{array}\right\}, B_{4}=\left\{\begin{array}{ccc}1 & 8 & 8 \\ 1 / 5 & 1 & 5 \\ 1 / 8 & 1 / 5 & 1\end{array}\right\}$
The maximum eigenvalue and eigenvector can be gained:

$\lambda_{\text {max }}^{(1)}=3.31, \omega^{(1)}{ }_{1}=\left\{\begin{array}{l}0.25 \\ 0.09 \\ 0.66\end{array}\right\}, \lambda^{(2)}{ }_{\text {max }}=3.12, \omega^{(1)}{ }_{2}=\left\{\begin{array}{l}0.58 \\ 0.29 \\ 0.13\end{array}\right\}$

$\lambda_{\text {max }}^{(3)}=3.30, \omega^{(1)}{ }_{3}=\left\{\begin{array}{l}0.62 \\ 0.24 \\ 0.14\end{array}\right\} \lambda^{(4)}{ }_{\text {max }}=4.05, \omega^{(1)}{ }_{4}=\left\{\begin{array}{l}0.19 \\ 0.24 \\ 0.58\end{array}\right\}$

The computation structure is as follows:

$$
\begin{aligned}
\omega^{(1)} & =\left(\omega_{1}^{(1)}, \omega_{2}^{(1)}, \omega_{3}^{(1)}\right) \\
& =\left\{\begin{array}{llll}
0.62 & 0.17 & 0.25 & 0.58 \\
0.24 & 0.24 & 0.09 & 0.29 \\
0.14 & 0.58 & 0.66 & 0.14
\end{array}\right\}
\end{aligned}
$$

$\omega=\omega^{(1)} \omega^{(0)}$

$$
\begin{aligned}
& =\left\{\begin{array}{llll}
0.26 & 0.59 & 0.66 & 0.19 \\
0.08 & 0.28 & 0.22 & 0.24 \\
0.66 & 0.15 & 0.16 & 0.58
\end{array}\right\}\left\{\begin{array}{l}
0.57 \\
0.06 \\
0.10 \\
0.27
\end{array}\right\} \\
& =\left\{\begin{array}{l}
0.40 \\
0.29 \\
0.31
\end{array}\right\}
\end{aligned}
$$


MATEC Web of Conferences

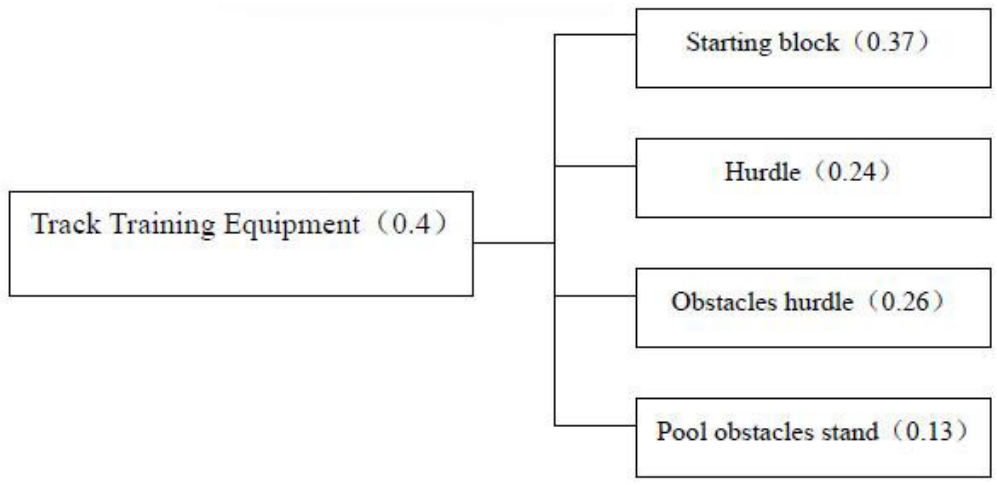

Figure 2. Weight distribution of track training equipment

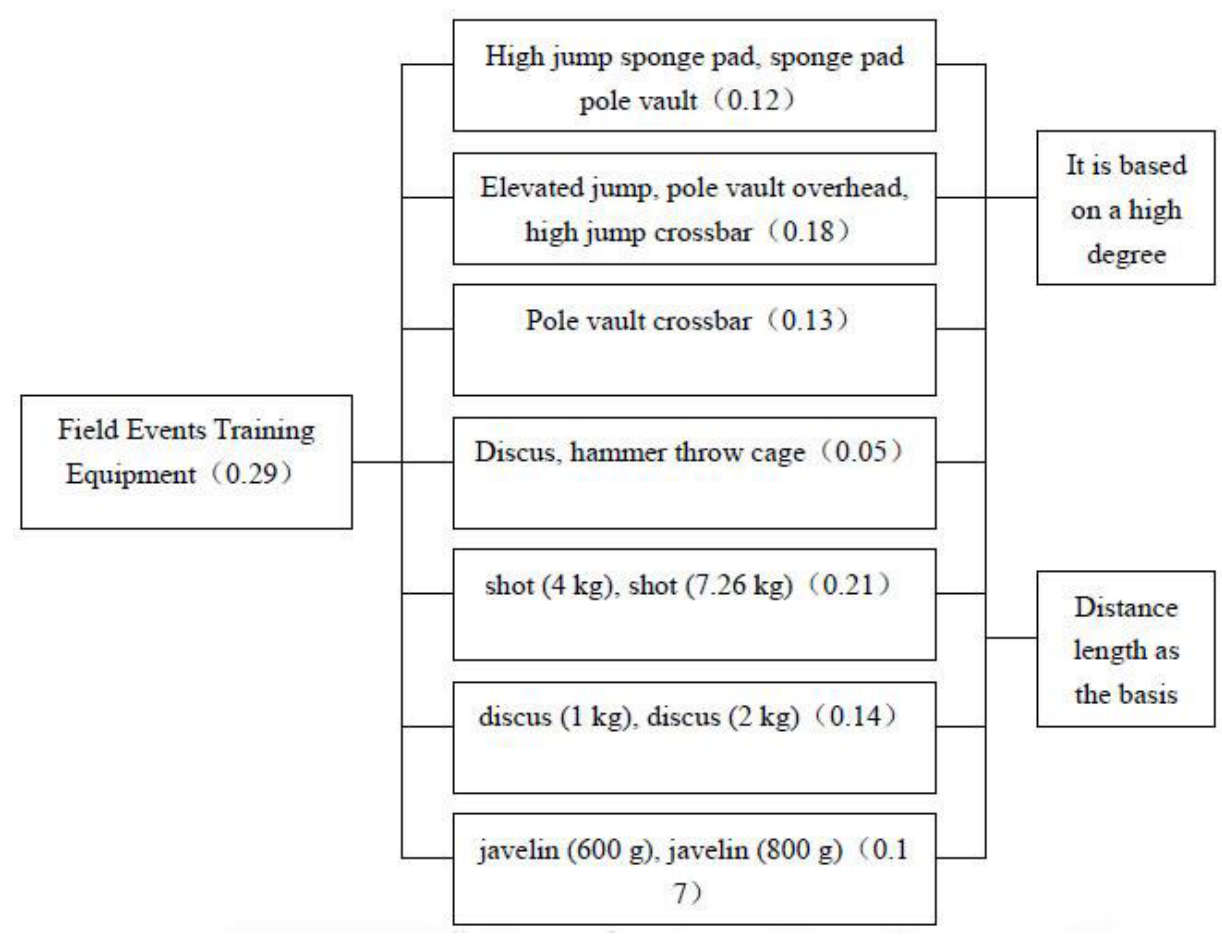

Figure 3. Weight distribution of field event training equipment

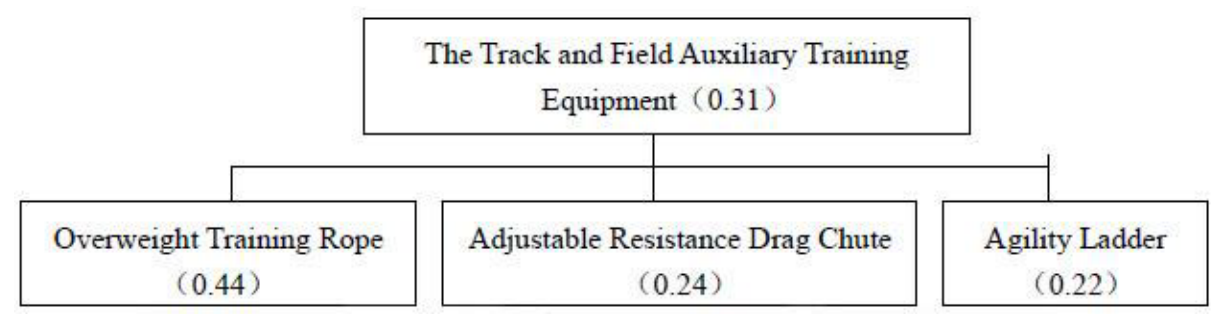

Figure 4. Weight distribution of track and field auxiliary training equipment 
The above are the weighted values of three first-level indexes of track training equipment, field events training equipment and auxiliary training equipment. In a similar way, the weighted values of second-level indexes have been gained as shown in Figures 2-4.

According to the gained proportion, for the athletes of track and field equipment training, it needs to be decided in the light of different situations. And based on the existing equipment, we should select and use the equipment according to the weighted values.

\section{CONCLUSION}

Based on the optimization of ID3 algorithm in the decision tree model and through the analysis of data sample, the proportions of the track training equipment, the field events training equipment and the track and field auxiliary training equipment have been respectively gained: $0.39,0.28,0.33$, which are compared with the result $\omega=\left\{\begin{array}{lll}0.4 & 0.29 & 0.31\end{array}\right\}^{\mathrm{T}}$ that has been gained by ordinary determining weights method. Indeterminate factors exist in the common algorithm, so the decision tree algorithm has better applicability and accuracy when accurate sample data exist.

\section{REFERENCES}

[1] Liang, J.X., \& Zhou, X.Y. 2008. An investigation and study for sports apparatus and equipment status quo of national track and field team. Report Review, 12 (16): 117-119.

[2] Liu, X.Z. 2001. The data processing method used in physical education. Beijing: Beijing Sport University Press.

[3] Yu, D.F., Gao, J.H. 2003. 20 years of retrospect and prospect of Chinese sports instrument and equipment. Chinese sports science and technology, (3).

[4] Yang, H.W., Zhao, M.H., Sun, J., Wang, X.Z. 2003. Decision tree based on hierarchical decomposition. Computer Engineering and Applications, 14 (1): 108-110.

[5] Lu, D.B. 2008. A research and application based on data mining algorithm of decision tree. Wuhan: Wuhan University of Technology.

[6] Hui, W., Zhang, L., Zhai, J.C. 2005. The research and improvement of decision tree algorithm in data mining. Journal of Liaoning Teachers College, 7 (4): 23-26. 